\title{
New Insight into Dynamic Mechanical Relaxation in N-butyl-N-(2-nitroxy-ethyl) Nitramine Plasticized Nitrocellulose through Molecular Dynamic Simulations
}

\section{Xiaofei Qi}

Xi'an Modern Chemistry Research Institute

ning yan ( $\triangle$ yanning_204@163.com )

Xi'an Modern Chemistry Research Institute https://orcid.org/0000-0002-4126-8738

Hongyan Li

Xi'an Modern Chemistry Research Institute

\section{Yu Zhao}

Xi'an Modern Chemistry Research Institute

\section{Peijin Liu}

Northwestern Polytechnical University

Qilong Yan

Northwestern Polytechnical University

\section{Research Article}

Keywords: Nitrocellulose, mechanical relaxation, molecular dynamic simulations

Posted Date: July 13th, 2021

DOI: https://doi.org/10.21203/rs.3.rs-682286/v1

License: (c) (1) This work is licensed under a Creative Commons Attribution 4.0 International License. Read Full License

Version of Record: A version of this preprint was published at Cellulose on January 30th, 2022. See the published version at https://doi.org/10.1007/s10570-021-04374-9. 
1 New Insight into Dynamic Mechanical Relaxation in N-butyl-N-(2-nitroxy-ethyl)

2 nitramine Plasticized Nitrocellulose through Molecular Dynamic Simulations

6 a. Xi'an Modern Chemistry Research Institute, Xi'an 710065, China

7 b. Science and Technology on Combustion, Internal Flow and Thermo-structure

8 Laboratory, Northwestern Polytechnical University, Xi'an 710072, China

9 Authors to whom correspondence should be addressed: yanning_204@163.com (Ning Yan); qilongyan@nwpu.edu.cn (Qilong Yan)

Abstract

We performed dynamic mechanical analysis (DMA) on nitrocellulose (NC) plasticized by an insensitive plasticizer N-butyl-N-(2-nitroxy-ethyl)nitramine (Bu-NENA). $\mathrm{NC} / \mathrm{Bu}-\mathrm{NENA}$ blend shows two mechanical relaxation processes in the temperature ranges of $-50 \sim-40^{\circ} \mathrm{C}$ and $30 \sim 40^{\circ} \mathrm{C}$, and their variations with deformation frequencies were studied. To explore further the effect of temperature on relaxation, the binary mixture model of NC/Bu-NENA was constructed, and molecular dynamic simulations were conducted. The simulated mean square displacements (MSD) show abrupt increase in the temperature range of $-50 \sim-40^{\circ} \mathrm{C}$ and $30 \sim 40^{\circ} \mathrm{C}$, which are consistent with those of the two relaxation processes observed in the DMA curves. Moreover, the free volume $\left(V_{\text {free }}\right)$ and torsion energy obtained from molecular dynamic simulations exhibit distinct increase at the temperature above $30^{\circ} \mathrm{C}$ and $-50^{\circ} \mathrm{C}$ respectively, reflecting the sudden enhancements on the mobility of polymer chain elements and the rotation of molecular bonds. Furthermore, the radial distribution function (RDF) associated with the intermolecular interactions reveals that the intensities of both hydrogen bond and van-der-vaals forces decrease with the increase of temperature, which is responsible for the decrease of storage modulus at high temperature. These computational and experimental studies reveal guidance to strengthening the $\mathrm{NC}$ base propellants in broad temperature range. 


\section{Key words}

Nitrocellulose, mechanical relaxation, molecular dynamic simulations

Nitrocellulose (NC), an energetic binder has been widely used in the fabrication of double base propellants, wherein NC serving as a major ingredient exerts great influence on the physical properties of propellants. Specifically, the mechanical properties of propellants at varied temperature play important role in dominating their practical applications. Nevertheless, $\mathrm{NC}$ features uneven rigidity nature, making it very difficult to uniformly mix with other ingredients, thus imposing adverse effect on the mechanical properties. In general, nitroglycerin (NG) was used as plasticizer to improve the processing of $\mathrm{NC}$, and the influence of $\mathrm{NG}$ on the physical properties of $\mathrm{NC}$ has been well investigated (Yang et al. 2017; Ma et al. 2008; Qi et al. 2019).

Recent works revealed that the replacement of $\mathrm{NG}$ with insensitive energetic plasticizers has significantly reduced the friction and impact sensitivities, which facilitate to improving the process security and the vulnerability of propellants (Chakraborthy et al. 2004; Damse et al. 2009; Yang et al. 2014; Reese et al. 2014) Moreover, the employment of insensitive plasticizers can strengthen the thermal stability and lower the vaporization rate compared with NG plasticizer, which contributes to enhancing mass homogeneity of NC base propellants during storage (Zhao et al. 2017; Wilker et al.2007; Ou et al. 2018). It is well known that the physical properties of $\mathrm{NC}$ show strong dependence on the additives used in propellants. In the reported works, the influences of solid fillers and plasticizers have been described for analyzing the physical properties of NC base propellants (Sun et al. 2018; An et al. 2012; Wu et al. 2020; Wang et al. 2019; Qi et al. 2020).

The static stress-strain relationship at different temperatures was depicted, which offer rational explanation for the factors that affect the physical properties. In comparison to static mechanical analysis, the changes in physical properties of $\mathrm{NC}$ can be better identified in the dynamic mechanical analysis (DMA), as DMA measurements possess advantages in identifying distinguishing the relaxation of polymer chains associated with the storage modulus (E'), loss modulus (E"), and tan $\delta$ (ratio of E"/E') 
as a function of temperature (De Paula et al. 2019). The influences of plasticizers on the dynamic mechanical properties of $\mathrm{NC}$ base propellants have been investigated, revealing the existence of two principal relaxation processes at high $\left(+40^{\circ} \mathrm{C}\right)$ and low $\left(-35^{\circ} \mathrm{C}\right)$ temperatures (Warren et al. 1988; Baker et al. 1987). Although, many applications of DMA have been explored for the study of dependence of the mechanical forces and energy loss on the temperature and frequency, fewer attention was paid on the manner whereby the plasticizers impact the transition behavior of NC. Especially, the molecular mechanism of the influence of plasticizer on the relaxation of NC is not well understood. As a main factor affecting the relaxation, the interaction between NC and plasticizer could be evaluated more precisely at high plasticizer content, which will impose great safety issues when using sensitive plasticizers.

In this contribution, we replaced NG with an insensitive plasticizer N-butyl-N-(2nitroxy-ethyl)nitramine (Bu-NENA) to overcome the safety restriction, and prepared NC/Bu-NENA composite with a mass ratio of 1:1. The dynamic mechanical properties of $\mathrm{NC} / \mathrm{Bu}-\mathrm{NENA}$ were studied as a function of temperature, aimed to distinguish the relaxations and transitions in the plasticized NC. Furthermore, molecular dynamics simulations were conducted to study the role of Bu-NENA in the relaxation behavior of $\mathrm{NC}$, and the simulated parameters such as mean squared displacement, free volume, and potential energy were correlated with the motion of molecular chains and chemical bonds. These experimental and simulative studies enable better explanation of the dependence of physical properties on the temperature, and reveal great potential guidance to strengthening the NC propellants in broad temperature range.

N-butyl-N-(2-nitroxy-ethyl) nitramine (Bu-NENA) was purchased from Haohua Chemical Group, Co., Ltd., China. Nitrocellulose (NC) was purchased from Sichuan Nitrocell Co., Ltd., China. All the reagents were used without further purification unless otherwise specified. The nitrocellulose pellets (nitrogen content $11.9 \mathrm{wt} \%$ ) were mixed with the same mass of Bu-NENA in a vertical kneading machine (HKV-II) under vacuum for $30 \mathrm{~min}$. Then, the mixture was solidified for $96 \mathrm{~h}$ at $70^{\circ} \mathrm{C}$, and the asprepared composite was cut into specimen with a dimension of $4 \mathrm{~mm} \times 4 \mathrm{~mm} \times 12 \mathrm{~mm}$. The dynamic mechanical analysis (DMA) was carried out on a DMA instrument 
(Netzsch 242) in a tension model. The DMA measurements ran at the temperature ranging from $-70^{\circ} \mathrm{C}$ to $110^{\circ} \mathrm{C}$ with a heating rate of $4 \mathrm{~K} \cdot \mathrm{min}^{-1}$, and the DMA curves were collected at the deformation frequencies of $1,2,5,10$ and $20 \mathrm{~Hz}$, respectively.

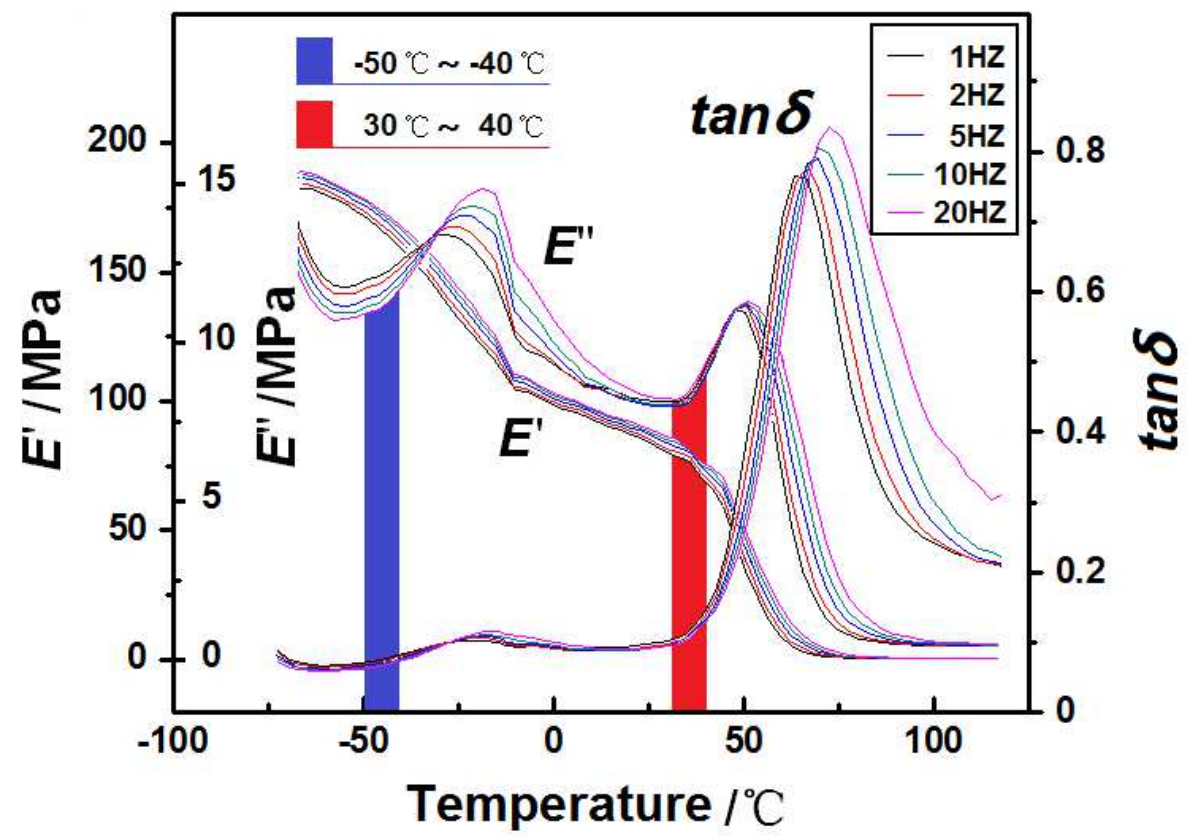

Fig.1 Dynamic mechanical curves of NC/Bu-NENA

Fig.1 shows the storage modulus E', loss modulus E" and the loss factor $\tan \delta$ of the NC/Bu-NENA composite obtained by DMA in tension mode at five different deformation frequencies. All the loss factor curves acquired at constant heating rate of $4 \mathrm{k}$. min show two peaks centered at low and high temperature correlating to the $\beta$ and $\alpha$ transitions respectively. The $\beta$ transition has been attributed to the motion of plasticizer molecules associated with $\mathrm{NC}$ side groups, whereas the designation of the $\alpha$ transition is less definite, which is assumed as the relaxation of the stiff $\mathrm{NC}$ chain rather than a transition (Warren et al. 1988; Baker et al.1987). The splitting phenomenon was not observed in the $\alpha$ peak, indicating that unique state exists in the glass transition process of the NC/Bu-NENA specimens.

Dynamic mechanical properties $\mathrm{NC} / \mathrm{Bu}-\mathrm{NENA}$ show strong dependence on the relaxation of polymer chains near the glass to rubber transition temperature $\left(\mathrm{T}_{\mathrm{g}}\right)$. Typically, increasing temperature above $T_{g}$ allows to increase the free volume of polymer, and thus lead to increased molecular mobility. Oppositely, the NC/Bu-NENA 
composite becomes hard and brittle below $\mathrm{T}_{\mathrm{g}}$, because of the reduced free volume at low temperature. In fact, DMA has been preferentially employed to study the relaxation and transition that are undetectable by DSC and TMA (Zhang et al. 2013; Saba et al. 2018; Meng et al. 2014; Bohn et al. 2015; Seyidoglu et al. 2020).

Herein, DMA was conducted at a constant heating rate and at different deformation frequencies. The storage (elastic) modulus (E'), loss (viscous) modulus (E") and loss factor $(\tan \delta)$ equivalent to the ratio $E^{\prime \prime} / E^{\prime}$ were recorded as a function of temperature. As shown in Fig.1, the storage modulus (E') gradually decreases with the increase of temperature in the case of all frequencies, implying that the energy storage per unit strain was lowered at high temperature. In general, mechanical relaxation occurs in the glass transition process of polymers, during which the flexibility and mobility of molecular chains undergo prominently changes. The decreased storage modulus is an indication of the increased mobility of $\mathrm{NC} / \mathrm{Bu}-\mathrm{NENA}$ chains at high temperature. Oppositely, increasing the deformation frequency in DMA leads to an increase of the $E$, value at the same temperature, and this is due to the strain-rate hardening effect of polymer chains at high deformation frequencies (Bohn et al. 2015;). The curves of loss modulus versus temperature show two peaks centered at around $-25^{\circ} \mathrm{C}$ and $50^{\circ} \mathrm{C}$, which are associated with the maximum energy loss arising from the internal friction and molecular rearrangement processes of polymer chains.

Moreover, the loss modulus curves show two inflection points at the temperature of $-50^{\circ} \mathrm{C}$ and $30^{\circ} \mathrm{C}$, corresponding to the onset temperatures of multiple relaxations of polymer chains. At the temperature of $-50{ }^{\circ} \mathrm{C}$, the side chain elements of $\mathrm{NC}$ start moving as the imported thermal energy overcomes their energy barrier. Increasing the temperature up to $30^{\circ} \mathrm{C}$ initiates the cooperative motion of numerous chain segments, which allows large scale deformation of $\mathrm{NC} / \mathrm{Bu}-\mathrm{NENA}$, and hence lowers the storge modulus. Besides, the $\tan \delta$ curve representing ratio of $E " / E$ ' was plotted against temperature, and the maximum value of $\tan \delta$ is a measure of glass transition temperature. The tan $\delta$ curves show two peaks reflecting the damping characteristics of $\mathrm{NC} / \mathrm{Bu}-\mathrm{NENA}$ at low and high temperatures, respectively. In fact, the intrinsic properties of polymer binders or plasticizers experience substantial change from glass 
state to rubber state by increasing temperature, which is an indicator of the change in the molecular mobility of the polymeric networks during the glass-rubber transition. Moreover, the maximum tan $\delta$ value and its corresponding glass transition temperature increase with the increase of frequency, which is due to the freeze of the polymer chain elements at high tensile frequency.
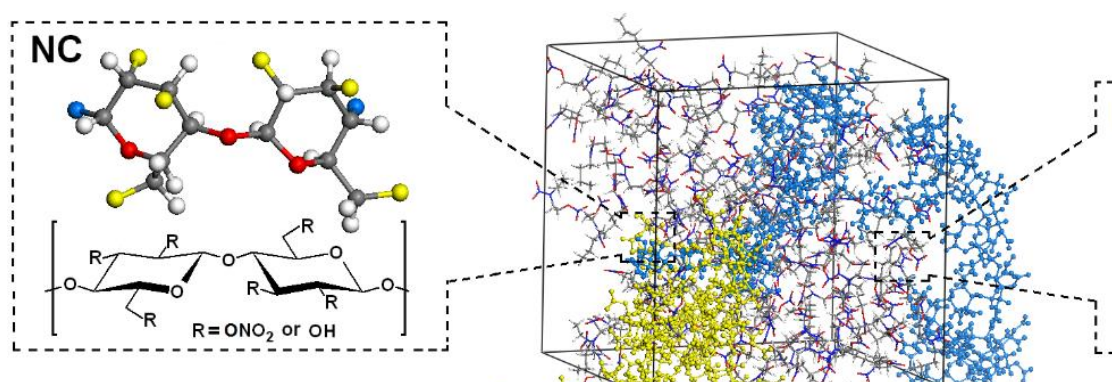

\section{NENA}

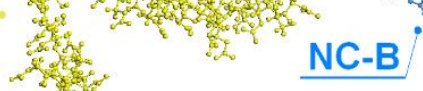

Fig.2 Molecular structures of NC and Bu-NENA, and the simulated primitive cell of the NC/Bu-NENA blend, NC-A and NC-B represent two different molecular chains of $\mathrm{NC}$ in the constructed model.

To gain deep insights into the variation of dynamic mechanical properties from the perspective of the motion of polymer chains, and explain the effect of temperature on the mechanical relaxation process of $\mathrm{NC} / \mathrm{Bu}-\mathrm{NENA}$ at molecular level, the molecular dynamic simulations were performed to study the atomistic model of $\mathrm{NC} / \mathrm{Bu}-$ NENA by means of Material Studio (Accelrys) according to our previous work (Qi et al. 2019). Given that the nitrogen content of $\mathrm{NC}$ is $11.9 \mathrm{wt} \%$, the average degree of substitution of $\mathrm{NC}$ is calculated to be 2.2 according to the reported equation (Jamal et al. 2020)

$$
D S=\frac{1.62 \times \% N}{14-0.45 \times \% N}
$$

Regarding the $\mathrm{NC} / \mathrm{Bu}-\mathrm{NENA}$ blends, the molecular chains of $\mathrm{NC}$ are coarse grained into the model of Gaussian chains, which are constituted by numerous basic NC units. Herein, 320 and 240 basic NC units were taken in the NC-A and NC-B Gaussian chains respectively. The simulations were conducted under a COMPASS (Condensed-phase Optimized Molecular Potentials for Atomistic Simulation Studies) force field. In detail, 2 molecular chains of NC were mixed with 98 molecules of Bu-NENA in the simulated 
primitive cell as shown in Fig.2, given that the mass ratio of NC and Bu-NENA is 1:1.

The NC/Bu-NENA was optimized by a 5000 step energy minimization to regulate unbalanced configurations. To achieve an equilibrium structure, a 100ps molecular dynamic simulation was performed on the system in the NPT ensemble under constant pressure with a time step of $1 \mathrm{fs}$. The simulations were carried out at different temperatures of $-80,-70,-60,-50,-40,-30,-20,-10,0,10,20,30,40,50,60,70$ and $80^{\circ} \mathrm{C}$, and the simulation results including the mean-square displacement, volume distribution, potential energy and radial distribution function were obtained.

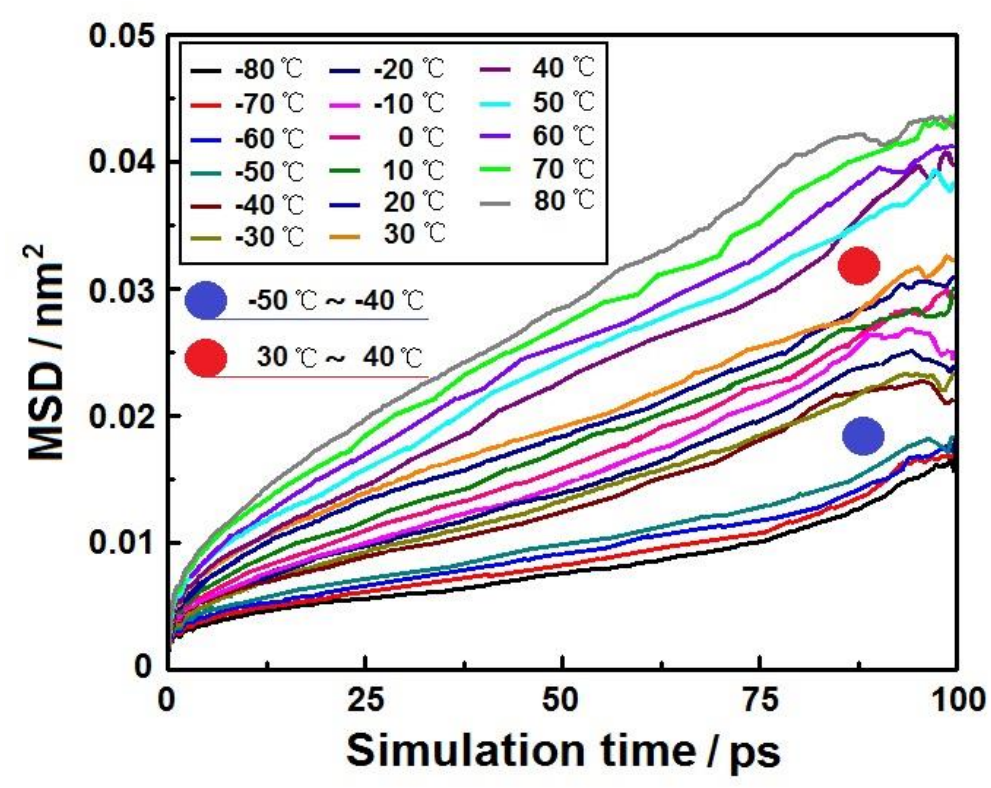

Fig.3 Mean-squared displacements of NC/Bu-NENA.

To probe the dynamics of Bu-NENA molecules and assess its influences on the relaxation of $\mathrm{NC}$, the mean-squared displacements (MSD) of plasticizer was estimated through molecular dynamics simulations. MSD is a statistical average of the trajectory of plasticizer molecules with simulation time and can be estimated from the production stage of MD simulation, during which the drift of the center of mass of the simulation box is subtracted, and expressed by the following equation:

$$
M S D=\left\langle\left|r_{t}-r_{0}\right|^{2}\right\rangle
$$

where $r_{0}$ and $r_{\mathrm{t}}$ represent the positions of the centre of mass of plasticizer molecules at time 0 and $t$ respectively, and the angular bracket represents the ensemble average.

Typically, MSD allows to describe the diffusion of plasticizer in NC/Bu-NENA blend. 
In brief, when the blend is frozen then MSD saturate, and the kinetic energy is too low to achieve thermal diffusion. Nevertheless, if the blend is not frozen then the MSD increases almost linearly with time, which allows to understand the dynamics of the blend from the slope of the MSD. Herein, molecular dynamic simulations were conducted to determine the MSD curves versus simulation time at $-80,-70,-60,-50,-40,-30,-20,-10,0,10,20,30,40,50,60$, 70 and $80{ }^{\circ} \mathrm{C}$ respectively, as shown in Fig.3. Notably, the simulations at higher temperature result in larger MSD values. The MSD curves show approximately linear relationship with respect to the simulation time, and the slop reflecting the mobility of plasticizer molecules increases with the increase of temperature. More interestingly, the slops of MSD exhibit two distinct increases in the temperature ranges from $-50^{\circ} \mathrm{C} \sim-$ $40^{\circ} \mathrm{C}$ and $30^{\circ} \mathrm{C} \sim 40^{\circ} \mathrm{C}$, suggesting that the molecular mobility of the plasticizer was significantly enhanced, which may be due to the sudden increased free volume of NC polymer in those two temperature ranges. The increased free volume facilitates to promote the relaxation of $\mathrm{NC}$ polymer chains. The relaxation processes disclosed in the MSD simulation are consistent with those revealed in DMA curves, verifying that $\mathrm{NC} / \mathrm{Bu}-\mathrm{NENA}$ possesses two principle mechanical relaxations in the temperature between -80 and $80^{\circ} \mathrm{C}$. It should be noted that the temperature at which the mechanical relaxation happens revealed in $\mathrm{MSD}$ is about $25^{\circ} \mathrm{C}$, which is lower than the glass transition temperature determined from the maximum tan $\delta$ value, and this delay is due to the viscoelastic nature of $\mathrm{NC} / \mathrm{Bu}-\mathrm{NENA}$ that leads to strain hysteresis of polymer chains under the action of external force. 


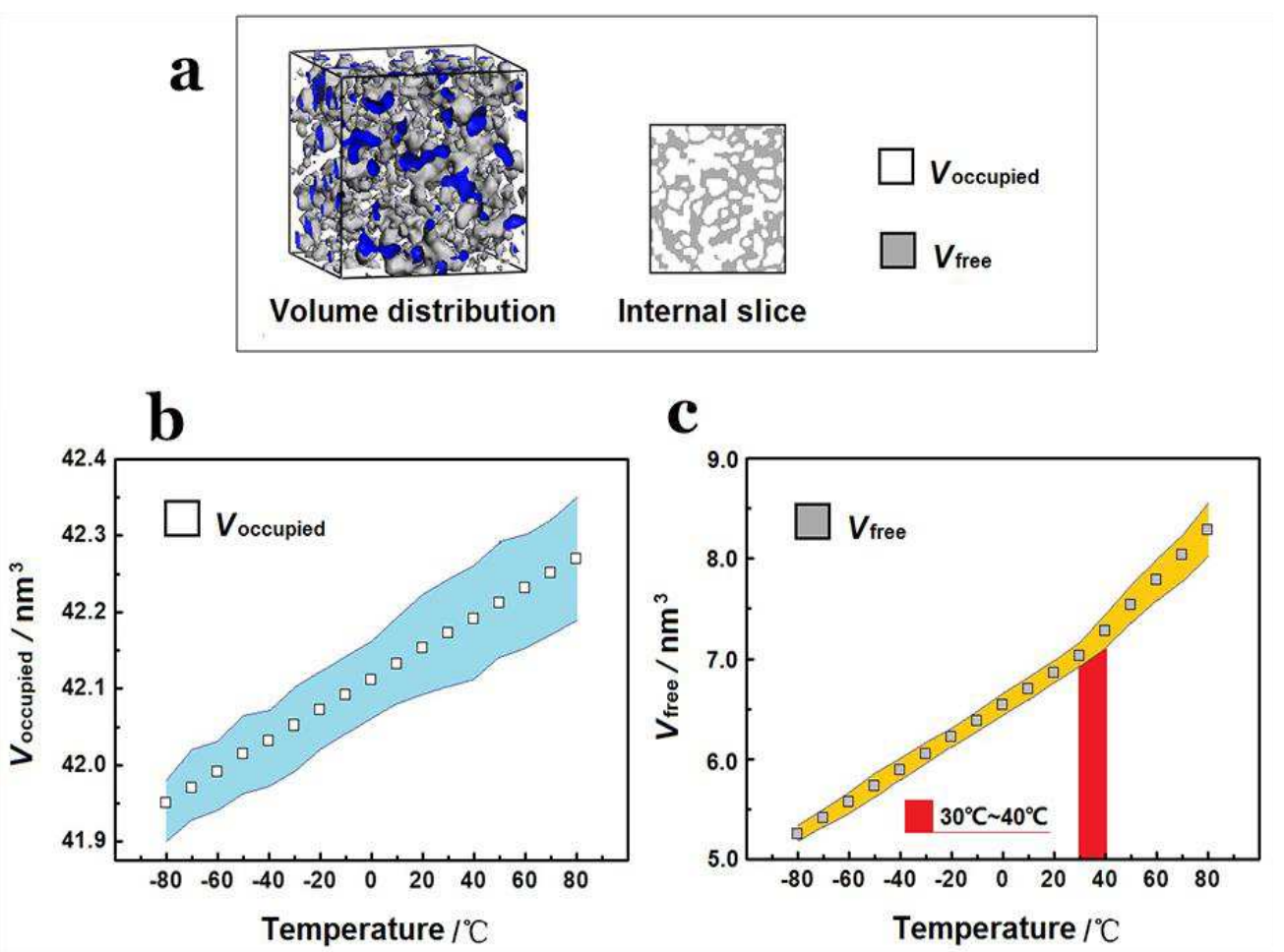

Fig.4 Volume distribution of NC/Bu-NENA at different temperatures

212 It is well established that the total volume of polymer consists of the volume occupied

213 by polymer chains ( $\left.V_{\text {occupied }}\right)$ and the interstitial spaces among the chains, namely free

214 volume ( $V_{\text {free }}$ ), among which $V_{\text {free }}$ strongly affects the motion and relaxation of 215 molecular chains. Hence, to further correlate the dynamic mechanical properties with 216 the motion of polymer chains, the molecular dynamic simulations were conducted to study the volume distribution in the NC/Bu-NENA blend. Fig.4a shows the volume distribution of NC/Bu-NENA at different temperature, where the distribution of $V_{\text {occupied }}$ and $V_{\text {free }}$ are visualized as white and grey areas in the cubic box, and the blue area indicates the cross section of free volume.

Fig. $4 \mathrm{~b}$ and $\mathrm{c}$ show the variation of $V_{\text {occupied }}$ and $V_{\text {free }}$ with respect to temperature. The $V_{\text {free }}$ value exhibits substantial increase from 5.258 to $8.287 \mathrm{~nm}^{3}$ with the temperature increasing from -80 to $80^{\circ} \mathrm{C}$, whereas the $V_{\text {occupied }}$ value shows only slightly increase from 41.951 to $42.270 \mathrm{~nm}^{3}$, attributed to the unveiling of the overlapped volume at high temperature. It is noteworthy that the $V_{\text {free }}$ value shows a faster increase when the temperatures are higher than $30^{\circ} \mathrm{C}$. This result indicates that a critical temperature exists, at which the mobility of $\mathrm{NC}$ molecular chains significantly changes, resulting in an acceleration of the mechanical relaxation of the molecular chains of NC. This variation 
of free volume is consistent with the simulation for the mean-squared displacements (MSD) in the temperature range of $30 \sim 40^{\circ} \mathrm{C}$, which allows to clarifying the mechanical relaxation and transition processes occurred at high temperature revealed in DMA. Actually, the sudden change of free volume is closely related to the glass transition of $\mathrm{NC} / \mathrm{Bu}-\mathrm{NENA}$ blend. The fast increase of free volume enables cooperative motion of numerous chain segments, and allows large scale deformation, with consequence of significant reduction of modulus.

\section{Potential energy}
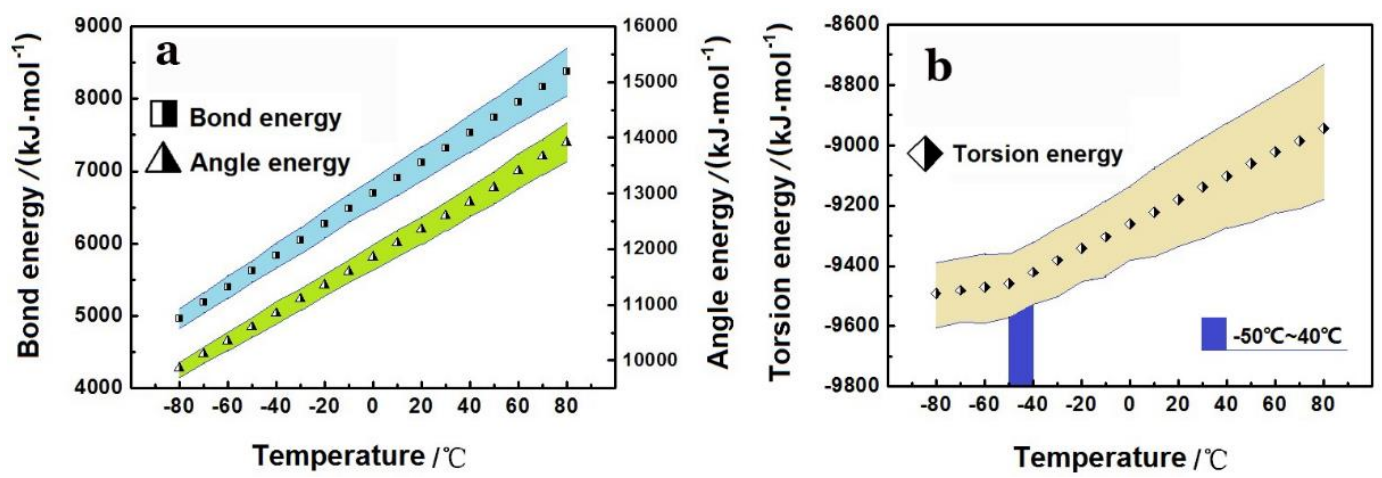

Fig.5 Potential energies of NC/Bu-NENA at different temperatures

In addition to free volume and mean square displacements, the potential energies consisting of intramolecular and intermolecular energies acquired from molecular dynamics simulation was adopted to study the mobility of polymer chains. Considering the arrangement of atoms in the molecular structure of $\mathrm{NC} / \mathrm{Bu}-\mathrm{NENA}$, the potential energy consists mainly of bond energy, angle energy and torsion energy of the molecular chains. Fig.5 shows the potential energy of NC/Bu-NENA as a function of temperature. Obviously, all the potential energies increase with the increase of temperature, suggesting that the intermolecular interaction between $\mathrm{NC}$ and $\mathrm{Bu}-\mathrm{NENA}$ was enhanced. The bond energy and angle energy exhibit almost linear increase as shown in Fig.5a, whereas the torsion energy displays two steps increase separated by the temperature region from -50 to $-40^{\circ} \mathrm{C}$, as highlighted in Fig.5b. This phenomenon shows a good agreement with the simulated mean square displacements at low temperature, indicating that the torsion movement in the molecular chains happened due to their shortened relaxation time in the temperature ranging from -50 to $-40^{\circ} \mathrm{C}$. This result can also explain the mechanical relaxation process taking place at the low 


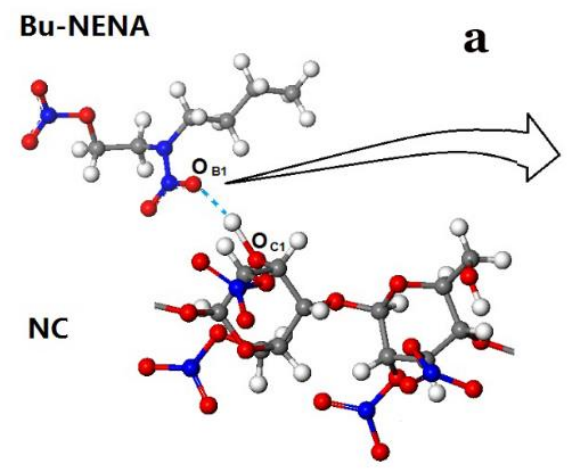

Fig.6 RDF curves for $\mathrm{O}_{\mathrm{C} 1}-\mathrm{O}_{\mathrm{B} 1}$ atom pair in the NC/Bu-NENA at different temperatures.

To understand the effects of temperature on the dynamic mechanical properties at the molecular level, the pair correlation function (PCF) was used to describe the intermolecular interaction between $\mathrm{NC}$ and $\mathrm{Bu}-\mathrm{NENA}$. PCF allows to depict the local spatial correlation of atom pairs, and enables measuring the atom density at certain distance from a reference atom. The pair correlation function can be defined as

$$
g^{(2)}\left(r, r^{\prime}\right)=\left\langle v^{(2)}\left(r, r^{\prime}\right)\right\rangle / n^{2}
$$

where $n$ is the particle number density, and $v^{(2)}\left(r, r^{\prime}\right)$ is pair density, which is expressed as:

$$
\begin{aligned}
& v^{(2)}\left(r, r^{\prime}\right)=\sum_{i} \sum_{j} \delta\left(r_{i}-r\right) \delta\left(r_{j}-r^{\prime}\right) \\
& (i \neq j)
\end{aligned}
$$

in which $r_{i}$ and $r_{j}$ is the position vector of atoms $i$ and $j$ respectively. The types and intensities of interaction force can be judged from the peak position and peak height in the PCF curves. Generally, the $r$ values of hydrogen bond and van der waal force are in the range of $0.20-0.31 \mathrm{~nm}$ and $0.31-0.50 \mathrm{~nm}$, respectively.

Herein, we studied on the potential interaction forces formed between the hydroxyl groups of $\mathrm{NC}$ and the nitrate groups of Bu-NENA. For simplicity, the oxygen atom in the hydroxyl group of $\mathrm{NC}$ was labeled as $\mathrm{O}_{\mathrm{C} 1}$, while the oxygen atom in the nitro group of $\mathrm{Bu}-\mathrm{NENA}$ was denoted as $\mathrm{O}_{\mathrm{B} 1}$. Fig.6a illustrates the interaction between $\mathrm{NC}$ and $\mathrm{Bu}-$ NENA at molecular level, and the variations of $\mathrm{O}_{\mathrm{C} 1}-\mathrm{O}_{\mathrm{B} 1}$ atomic force with respect to 
temperature are shown Fig.6b. The RDF curve for the atom pair $\mathrm{O}_{\mathrm{C} 1}-\mathrm{O}_{\mathrm{B} 1}$ at $-80^{\circ} \mathrm{C}$ displays a peak at $0.259 \mathrm{~nm}$, corresponding to a $\mathrm{g}(\mathrm{r})$ value of 1.606 , which indicates that the type of atomic force $\mathrm{O}_{\mathrm{C} 1}-\mathrm{O}_{\mathrm{B} 1}$ belongs to the hydrogen bond. The second peak observed at $r=0.447 \mathrm{~nm}$ corresponds to the $\mathrm{g}(\mathrm{r})$ value of 0.887 , and this peak is associated with the van der waal forces between the oxygen functionalities in NC and Bu-NENA. Notably, the intensities of both peaks in RDF curve decrease with the increase of temperature, suggesting that both hydrogen bond and van der waal force decrease. The decrease of intermolecular interaction enables enhancement on the flexibility of NC molecular chains, which interprets the decrease of storage modulus with increasing temperature.

In summary, NC/Bu-NENA was prepared through a conventional kneading approach.

DMA reveals two main relaxation processes at high and low temperatures, which correlate with the movements of the molecular chains and the torsion of the molecular bonds. Molecular dynamics simulations were conducted to verify the experimental results. The simulated mean square displacements and free volume demonstrate abrupt increase in the temperature range of $30 \sim 40^{\circ} \mathrm{C}$, which confirm the mechanical relaxation and transition processes revealed in DMA. Moreover, the simulated torsion energy displays significant increase in the temperature range from -50 to $-40^{\circ} \mathrm{C}$, which verifies

Conflict of interest The authors declare that they have no conflict of interest.

\section{References}

Yang J, Gong X, Wang G (2017) Density functional theory and molecular dynamic investigations on the energetic and mechanical properties of 
nitrocellulose/nitroglycerin/pentaerythritol diazido dinitrate composites. Polymer Composites 38:192-198. https://doi.org/10.1002/pc.23575

Ma X, Zhu W, Xiao J, Xiao H (2008) Molecular dynamics study of the structure and performance of simple and double bases propellants. J Hazard Mater 156: 201 207. https://doi.org/10.1016/j.jhazmat.2007.12.0685

Qi X, Li H, Zhao Y, Yan N (2019) Comparison of the structural and physical properties of nitrocellulose plasticized by N-butyl-N-(2-nitroxy-ethyl) nitramine and nitroglycerin: Computational simulation and experimental studies. J Hazard Mater 362: 303-310.https://doi.org/10.1016/j.jhazmat.2018.09.033

Chakraborthy T, Raha K, Omprakash B (2004) A study on gun propellants based on butyl-NENA. J Energy Mater 22: 41-53. https://doi.org/10.1080/07370650490438293

Damse R, Omprakash B,Tope B, Chakraborthy T, A. Singh (2009) Study of Nnbutyl-N-(2-nitroxyethyl)nitramine in RDX based gun propellant. J Hazard Mater 167: 1222-1225.https://doi: 10.1016/j.jhazmat.2008.12.095.

Yang J, Gong X, Wang G (2014) Theoretical studies on the plasticizing effect of DIANP on NC with various esterification degrees. Comp. Mater. Sci. 95: 129-135. https://doi.org/10.1016/j.commatsci.2014.07.024

Reese D, Groven L, Son S (2014) Formulation and Characterization of a New Nitroglycerin-Free Double Base Propellant. Propellants Explos Pyrotech 39: 205210. https://doi.org/10.1002/prep.201300105

Zhao B, Zhang T, Wang Z, Sun S, Ge Z, Luo Y (2017) Kinetics of Bu-NENA evaporation from Bu-NENA/NC propellant determined by isothermal thermogravimetry. Propellants Explos Pyrotech 42: 253-259. https://doi.org/10.1002/prep.201600054

Wilker S, Gjersoe R, Stenslands P, Becher C (2007) Stability analysis of n-butylnitratoethylnitramine (Bu-NENA) Cent Eur J Energy Mater 4:59-80.

Ou Y, Sun Y, Guo X, Jiao Q (2018) Investigation on the thermal decomposition of hydroxyl terminated polyether based polyurethanes with inert and energetic plasticizers by DSC-TG-MS-FTIR. J Anal Appl Pyrolysis 132:94-101. 
https://doi.org/10.1016/j.jaap.2018.03.011

Sun S, Zhang T, Zhao B, Zhang G, Li X, Luo Y (2018) Influence of polytetrafluorethylene on the mechanical and safety properties of a composite modified double base propellant. Cent Eur J Energy Mater 15:468-484. $10.22211 /$ cejem/92444

An, CW; Li, FS; Wang, JY; Guo, XD (2012) Surface Coating of Nitroamine Explosives and Its Effects on the Performance of Composite Modified Double-Base Propellants. J Propul Power 28: 444-448. https://doi.org/10.2514/1.B34061

Wu Z, Liu N, Zheng W, Chen J, Song X, Wang J, Cui C, Zhang D, Zhao F. (2020) Application and properties of CL-20/HMX cocrystal in composite modified double base propellants, Propellants Explos Pyrotech 45:92-100. https://doi: 10.1002/prep.201900245

Wang J, Yang L, Zheng W, Zhang J (2019) Study on comparative performance of CL20/RDX-based CMDB propellants. Propellants Explos Pyrotech 44:1175-1182. https://doi.org/10.1002/prep.201900029

Qi L, Ma Z, Liang J (2020) Effect of solid additives on the rheological property of nitroglycerin plasticized nitrocellulose. Appl Rheol 30: 14-26. https://doi.org/10.1515/arh-2020-0002

De Paula A, Uliana F, Filho E, Soares K, Luz P (2019) Use of DMA-material pocket to determine the glass transition temperature of nitrocellulose blends in film form Carbohyd Polym 226:115288. https://doi.org/10.1016/j.carbpol.2019.115288

Warren R (1988) Transitions and relaxations in plasticized nitrocellulose. Polymer 29: 919-923.

Baker F, Privett G (1987) Dynamic mechanical studies of nitrocellulose nitroglycerine mixtures polymer. 28:1121-1126. https://doi.org/10.1016/0032-3861(87)90253-9

Zhang Y, Adams R, Silva L (2013) A rapid method of measuring the glass transition temperature using a novel dynamic mechanical analysis method. J Adhesion 89: 785-806. https://doi.org/10.1080/00218464.2013.763677

Saba N, Jawaid M (2018) A review on thermomechanical properties of polymers and fibers reinforced polymer composites. $J$ Ind Eng Chem 67: 1-11. 
Meng F, Geng J, Besser F, Kramer M, Ott R (2014) Glass transition in a marginal glassforming alloy studied by dynamic mechanical analysis. J Appl Phys 116: 223505. https://doi.org/10.1063/1.4904195

Seyidoglu T, Bohn M (2021) Effects of four isocyanates and four plasticizers on the thermomechanical and tensile properties of hydroxylterminated polybutadiene elastomers and the effect of solid particle filling. J Appl Polym Sci. 138: 50362. https://doi.org/10.1002/app.50362

Bohn M Modelling of loss factors of elastomer binders of high explosive charges and composite rocket propellants to separate binder fractions with different molecular mobility used to follow ageing. Seminar on New Trends in Research of Energetic Materials, Proceedings. Pt.2: April 15-17. 2015 Pardubice, Czech Republic

Jamal S, Roslan N, Shah N, Noor S, Ong K, Yunus W (2020) Preparation and characterization of nitrocellulose from bacterial cellulose for propellant uses. Materials Today: Proceedings. 29: 185-189. https://doi.org/10.1016/j.matpr.2020.05.540 